\title{
Effects of Combined Warmed Preoperative Forced- air and Warmed Perioperative Intravenous Fluids on Maternal Temperature During Cesarean Section: a prospective, randomized, controlled clinical trial
}

\author{
tingting $\mathbf{N i}$ \\ hospital \\ Zhen-feng Zhou \\ hospital \\ Bo He \\ Hospital
}

Qing-he Zhou ( $\sim$ zqh@jxey.com )

\section{Research article}

Keywords: Cesarean section, Spinal anesthesia, Warming

Posted Date: January 15th, 2020

DOl: https://doi.org/10.21203/rs.2.20668/v1

License: (c) (i) This work is licensed under a Creative Commons Attribution 4.0 International License. Read Full License

Version of Record: A version of this preprint was published at BMC Anesthesiology on February 26th, 2020. See the published version at https://doi.org/10.1186/s12871-020-00970-7. 


\section{Abstract}

Background: Preventing the frequent perioperative hypothermia incidents that occur during elective caesarean deliveries would be beneficial. This trial aimed at evaluating the effect of preoperative forcedair warming alongside perioperative intravenous fluid warming in women undergoing cesarean sections under spinal anesthesia.

Methods: We randomly allocated135 women undergoing elective cesarean deliveries to either the intervention group (preoperative forced-air and intravenous fluid warmings, $n=69$ ) or the control group (no active warming, $n=66$ ). The primary outcome measure was the change from the core baseline temperature to that at the end of the procedure. Secondary outcomes included thermal comfort scores, the incidences of shivering and hypothermia $\left(<36^{\circ} \mathrm{C}\right)$, the core temperature on arrival at the postanesthesia care unit, neonatal axillary temperature at birth, and Apgar scores.

Results: Two-way repeated measures ANOVA revealed significantly different core temperature changes (from the pre-spinal temperature to that at the end of the procedure) between groups $(F=13.022, P$ $<0.001)$. The thermal comfort scores were also higher in the intervention group than in the control group $(F=9.847, P=0.002)$. The overall incidence of perioperative hypothermia was significantly lower in the intervention group than in the control group $(20.6 \%$ vs. $51.6 \%, P<0.0001)$.

Conclusions: Warming preoperative forced-air and perioperative intravenous fluids may prevent maternal hypothermia, reduce maternal shivering, and improve maternal thermal comfort for patients undergoing cesarean sections under spinal anesthesia.

Trial registration: The study was registered with the Chinese Clinical Trial Registry (registration number: ChiCTR1800019117) on October26, 2018. Keywords: Cesarean section, Spinal anesthesia, Warming

\section{Background}

Neuraxial (spinal, epidural, or combined spinal-epidural techniques) anesthesia is the preferred anesthetic technique for cesarean deliveries. Perioperative hypothermia is a commonly reported side effect of regional anesthesia affecting up to $60 \%$ of patients undergoing cesarean deliveries under spinal anesthesia ${ }^{[1-4]}$. The hypothermia can cause numerous complications including postoperative wound infections, increased blood loss and transfusion requirements, myocardial ischemia, high risk of coagulopathy, shivering, increased hospital stay, and patient discomfort ${ }^{[5-12]}$. Neonatal outcomes such as birth temperature and Apgar scores have also been linked to maternal temperature ${ }^{[13,14]}$.

Perioperative hypothermia under spinal anesthesia has different etiologies, but mostly it is caused by spinal anesthesia altering thermoregulation and reducing the threshold for vasoconstriction and shivering ${ }^{[15]}$. Neuraxial anesthesia decreases the thermoregulatory vasoconstriction below the sensory blockade level, leading to heat loss by redistribution of heat from the core to the periphery ${ }^{[16]}$. The core-toperipheral redistribution of body heat is difficult to treat, but it should be preventable by prewarming the 
periphery compartment ${ }^{[17]}$. Prewarming increases the heat content in the periphery of the patient and reduces the core-to-peripheral tissue temperature gradient, which otherwise promotes the heat redistribution after spinal anesthesia ${ }^{[18]}$. Intraoperative forced-air warming has been shown to be uncomfortable for the patient and may affect the early maternal-newborn bonding ${ }^{[3]}$. Unlike the forced-air warming, warmed intravenous fluids do not disturb the operation during the surgical procedure. Despite the existence of prospective studies on active warming during cesarean delivery, no consensus regarding its efficacy exists. Studies have suggested that single-modality interventions to prevent hypothermia (forced-air or intravenous fluid warmings) result in only marginal or no benefit for patients undergoing cesarean sections $[1,4,19,20]$.

Therefore, we aimed to evaluate the effect of the combined application of 30 minutes of preoperative warm forced-air and perioperative warm intravenous fluids in women receiving spinal anesthesia for cesarean deliveries.

\section{Methods}

\section{Study Design}

The Ethical Committee of Ningbo N0.7 Hospital approved this study, which follows the tenets of the Declaration of Helsinki, and we pre-registered it at http://www.chictr.org.cn/index.aspx (ChiCTR1800019117). This study adheres the applicable CONSORT guidelines. We enrolled healthy pregnant women undergoing elective cesarean deliveries under spinal anesthesia after obtaining their informed consents. American Society of Anesthesiologists physical status I-II parturients, aged 18 to 40 years, with more than 37-week gestations, singleton pregnancies, and scheduled for cesarean delivery under spinal anesthesia were eligible for enrollment. We excluded women with coagulation abnormalities, thyroid disease, cesarean delivery using epidural or general anesthesia, and baseline temperatures $\geq 37.5^{\circ} \mathrm{C}$.

\section{Study Protocol}

After obtaining the signed informed consents, we randomly allocated eligible participants to either the control or the intervention groups. Randomization was computer-generated using Microsoft Excel's random number generator, and we concealed allocations using sequentially numbered opaque sealed envelopes.

All women fasted for eight hours before the cesarean section. Once in the preoperative waiting area, the women in the intervention group received 30 minutes of upper body preoperative warming using a forcedair warming device (EQ-5000 230V, Smiths Medical ASD, Rockland, USA) set to $43^{\circ} \mathrm{C}$ and nurses established intravenous accesses. The women in the intervention group received Ringer's lactate solution pre-warmed to $37^{\circ} \mathrm{C}$ through a $3 \mathrm{MRanger}{ }^{\mathrm{TM}}$ Fluid Warmer until the end of the procedure. We monitored the patients during the interventions. We discontinued the intervention in cases in which the parturients 
experienced adverse side effects related to warming such as diaphoresis or nausea and vomiting, or if the core thermometer was $>37.5^{\circ} \mathrm{C}$. After prewarming, we immediately transferred the term parturients to the operating room (OR). The women in the control group received usual care consisting of no active warming and they received the intravenous fluid at room temperature throughout the procedure. We recorded data on vital signs including heart rate, blood pressure, hemoglobin peripheral saturation, and baseline core temperature in the preoperative area. The same operator measured patients' core temperatures using an infrared tympanic thermometer (PRO6000, Braun, Marlborough, MA USA 01752) with disposable covers, and recorded the average value of three measurements. The hospital maintained central control of the temperatures of the preoperative area, OR, and post-anesthesia care unit (PACU), and we obtained the temperature readings from the thermostat.

An anesthesiologist not involved in the study applied all spinal anesthesias at the L3-4 interspace, with 2 $\mathrm{mL}$ of $0.5 \%$ plain bupivacaine, using a 25 -gauge Quincke needle. The surgeon commenced the operations once a sensory blockade above the T4 level was achieved according to the results of pinprick tests. After the operation, all patients were transferred to the PACU covered with a cotton sheet and a blanket.

We obtained values for core temperature, maternal thermal comfort scores, and the incidences of shivering and hypothermia at the following timepoints: $T_{0}=$ baseline, $T_{1}=$ pre-spinal, $T_{2}=$ post-spinal, $T_{3}$ $=$ after 15 minutes in the $\mathrm{OR}, \mathrm{T}_{4}=$ after 30 minutes in the $\mathrm{OR}, \mathrm{T}_{5}=$ surgery end, $\mathrm{T}_{6}=\mathrm{PACU}$ arrival, $\mathrm{T}_{7}=$ after 15 minutes in the PACU, $T_{8}=$ after 30 minutes in the PACU. According to Guidelines ${ }^{[21]}$, we defined maternal hypothermia as a core temperature $<36^{\circ} \mathrm{C}$. We assessed thermal comfort scores using a verbal numerical scale on which we defined 0 as completely unsatisfied with the "thermal comfort" and 100 as completely satisfied. We graded shivering during and after the cesarean section according to the Bedside Shivering Assessment Scale ( 0 , no shivering; 1 , shivering localized to the core and neck; 2 , shivering including the upper extremities; 3 , total body shivering ${ }^{[22]}$. The anesthesiologist provided meperidine according to their own criteria. A midwife recorded neonatal axillary temperature, and Apgar scores at 1 and 5 minutes after birth.

We defined bradycardia as a heart rate $<50$ beats $/ \mathrm{min}$, and treated it with $0.5 \mathrm{mg}$ of intravenous atropine. When the systemic pressure decreased more than $30 \%$ of the baseline pressure or dropped below 90 $\mathrm{mmHg}$, we administered ephedrine $(5 \mathrm{mg})$. The baseline systolic blood pressure was measured three times (every 2 minutes) in the preoperative area, and we recorded the average of those measurements.

We recorded demographic data (age, height, weight, parity, and gravidity) and surgical and anesthetic variables (total volume of intravenous fluids, estimated blood loss, duration of surgery, and the ambient temperatures in the preoperative area, $\mathrm{OR}$, and PACU).

\section{Statistical Analyses}

The primary outcome measure of this randomized control trial was the core temperature change from baseline to the end of the surgical procedure. Secondary outcomes included thermal comfort scores 
during the operation, the incidence of shivering and hypothermia $\left(<36^{\circ} \mathrm{C}\right)$, the core temperature on the arrival at the PACU, neonatal axillary temperature at birth, and Apgar scores at 1 and 5 minutes).

We used a standard deviation of $0.4^{\circ} \mathrm{C}$ for our calculations based on the results of the Chung et al study (they found a $0.4^{\circ} \mathrm{C}$ higher temperature decline in their control group than in the intervention group when measured 45 minutes after initiating the surgical procedure) ${ }^{[23]}$. Our sample size calculation revealed that a total of 50 patients were required (power $=0.9 ; \mathrm{a} /$ Pvalue $=0.05$; variability $/ \mathrm{SD}= \pm 0.4^{\circ} \mathrm{C}$; dropout, $20 \%$ ).

We expressed normally distributed continuous data as means \pm SDs, and compared variables between study groups using the Student $t$ test. Nonparametric data are presented as medians (interquartile ranges), and compared between study groups using the Mann-Whitney $\mathrm{U}$ test. We investigated associations among discrete variables using the $\mathrm{c} 2$ or Fisher exact tests. Two-way repeated measures ANOVA was applied with change from baseline as the dependent variable, and the intervention, time, and the treatment multiplied by time interaction as independent variables. We also used two-way repeated measures ANOVA to assess the core temperature change and the thermal comfort between groups at each timepoint. We performed all statistical analyses using the SPSS software (version 22.0, SPSS, Chicago, IL, USA). We considered P-values $<0.05$ as statistically significant.

\section{Results}

We considered 144 patients for eligibility, and excluded 9 before randomization. In the end we randomly allocated 135 patients to one of the two groups ( 69 women to the intervention group, and 66 to the control group). We had to exclude one patient from the intervention group and two patients from the control group due to failed spinal anesthesias (Fig. 1). The demographic and obstetric characteristics, as well as the surgical and anesthetic values, were did not differ significantly between the two groups. The preoperative area, OR, and PACU temperatures were similar for the two groups (Table 1).

Our two-way repeated measures ANOVA analysis revealed a significant difference in the core temperature changes fromthe $T_{1}$ to $T_{7}$ timepointsbetween the two groups $(F=13.022, P<0.001)$, and the group'time interaction difference was also significant $(F=23.195, P<0.001)$. The patients in the intervention group experienced higher perioperative mean temperatures during the procedure (time from $T_{1}$ to $T_{3}, P<0.001$; time from $\mathrm{T}_{4}$ to $\mathrm{T}_{7}, P<0.05$ ) than those in the control group. In the control group, the core temperature was decreased at all the time points compared to the baseline. We also found a slight decline in the core temperatures from the baseline during the procedure (except $\mathrm{T}_{2}$ ) in the intervention group (Fig.2).

Thermal comfort scores were higher in the intervention group than in the control group ( $F=9.847$, $P=0.002)$, the group ' time interaction difference was also significant ( $F=2.750, P=0.008)$. The maternal thermal comfort scores differed significantly between two groups from the $T_{2}$ to $T_{6}$ time points. In comparisons with the baseline thermal comfort scores, the time points in the control group (except $\mathrm{T}_{1}$ ) 
and those in the intervention group (except $\mathrm{T}_{1}$ and $\mathrm{T}_{6}$ ) all exhibited decreased thermal comfort scores (Fig. 3).

Core temperatures on arrival at the PACU were greater in the intervention group $\left(36.2 \pm 0.4^{\circ} \mathrm{C}\right)$ than in the control group $\left(35.5 \pm 0.3^{\circ} \mathrm{C}\right), P=0.007$. The incidences of shivering were $56.3 \%$ in the control group and $19.1 \%$ in the intervention group during the surgical procedure $(P<0.001)$, and the shivering assessment scores were higher in the control than in the intervention group. The overall incidence of perioperative hypothermia was significantly lower in the intervention group than in the control group $(P<0.001)$. Neonatal outcomes were similar between the two groups(Table 2).

\section{Discussion}

In our study, our intervention with 30 minutes preoperative forced-air warming and perioperative administration of warmed intravenous fluids reduced the extent of core temperature decline, decreased the incidence of preoperative hypothermia and shivering, and improved maternal comfort in patients undergoing cesarean section with spinal anesthesia as opposed to the outcomes in the control group patients.

The results of our study are similar to those of the study by Chung et al in which preoperative forced-air warming prevented hypothermia and shivering in patients undergoing elective cesarean delivery with spinal anesthesia ${ }^{[23]}$. However, in that study the difference in maternal temperatures between groups was evident only at one timepoint (45 minutes after prewarming). Therefore, the impact of their single intervention was likely smaller than the impact of our combined warming of forced-air and intravenous fluids. The combined active warming modalities applied in our intervention group maintained a significantly higher mean temperature nearly throughout the entire surgical procedure (at the seven timepoints). The intervention group had a significantly higher temperature on arrival at the PACU compared with the control group. Similarly, our study also demonstrated that our combined warming technique can reduce the incidence of perioperative hypothermia significantly $(20.6 \%$ in the intervention group compared with $56.3 \%$ in the control group).

Unlike forced air-warming which warms the patient from the outside, the warming of intravenous fluids prevents hypothermia by offsetting the $0.25^{\circ}$ Creduction in body temperature that occurs with each liter of intravenous fluids administered at room temperature ${ }^{[24]}$. To minimize spinal hypotension, women undergoing caesarean delivery often receive large volumes of intravenous fluid intraoperatively. Thus, fluid warming may be particularly important and effective during caesarean deliveries ${ }^{[25]}$. These findings agree with those in other studies. Horn et al found that 15 minutes of preoperative warming provided additional efficacy when added to warmed intravenous fluids in the setting of epidural anesthesia, resulting in an average $1^{\circ} \mathrm{C}$ difference between control and intervention groups at the end of the operations ${ }^{[13]}$. Unlike forced air-warming during all the surgical procedure ${ }^{[25]}$, brief period of prewarming, 
would be more acceptable to awake patients, easy to accommodate and could be combined with intraoperative warming, which is undoubtedly effective once the redistribution period has passed.

The combined technique has the potential to minimize maternal temperature drops. Similarly, in a study by De Bernardiset al, thermal gowns and warmed intravenous fluids decreased the patient temperature drops and the incidence of shivering as compared to the same variables in the control group ${ }^{[26]}$. In contrast, in Munday et al's study, 20 minutes of preoperative forced-air warming with intravenous fluid warming did not prevent temperature drops in women undergoing cesarean delivery ${ }^{[27]}$. However, the OR ambient temperature was lower in that study $\left(21.4^{\circ} \mathrm{C}\right)$. The time between the end of the warming regime and the OR entry was longer than those in our study. In their study, the time interval was smaller than 20 minutes, but some women may have experienced longer delays. Therefore, their study design may have been less powerful than ours to detect differences between two groups.

In our study, shivering was significantly less common in the patients who were actively warmed, a finding that may be explained by the significantly higher core temperatures in the combined active warming patients than in the controls. The intensity and incidence of shivering may indicate the severity of hypothermia. Our study showed that the overall incidence of perioperative hypothermia decreased significantly in the intervention group compared to the incidence in the control group. Shivering is both thermogenic accompanied by vasoconstriction or non-thermogenic as that induced by catecholamines resulting from pain or anxiety ${ }^{[28]}$. A meta-analysis demonstrated that warmed intravenous fluids are effective at reducing the incidence of hypothermia and shivering ${ }^{[29]}$. In addition, our combined active warming interventions improved the thermal comfort scores of the patients in the intervention group as opposed to the score in the control group. Thermal comfort scores are subjective measures of patient comfort during the perioperative period, and may differ from actual temperature measurements and do not necessarily reflect recorded shivering episodes. Results of studies ${ }^{[20,30,31]}$ and a metaanalysis ${ }^{[29]}$ suggest that forced-air warming can improve thermal comfort scores.

We found no significant differences in neonatal outcomes between the two groups, which is not surprising given our small sample size and our limited neonatal outcome measurements. Further studies specifically powered to evaluate the impact of active warming on neonatal outcomes are still required.

We are aware of the limitations in our study. Our infrared tympanic thermometers lack evidence of their quality and accuracy. However, they are not invasive and provide an acceptable and comfortable measurement to patients. Also, we did not use intrathecal morphine as a spinal anesthetic. However, many institutions prefer to use intrathecal opioids for postoperative analgesia after cesarean delivery, so this may affect the generalizability of our study. A study has shown that intrathecal morphine administration may exacerbate hypothermia. ${ }^{[19]}$

\section{Conclusion}


In all, preoperative forced air-warming combined with perioperative intravenous fluid warming may prevent maternal hypothermia, reduce maternal shivering, and improve maternal thermal comfort in those undergoing cesarean section with spinal anesthesia.

\section{Abbreviations}

OR: operating room; PACU: post-anesthesia care unit; BMI: body mass index; ASA, American Society of Anesthesiologists; EBL, estimated blood loss.

\section{Declarations}

\section{Acknowledgements}

None.

\section{Authors' contributions}

QHZ : contributed to the design of the work, and writing the manuscript.TTN: contributed to performing all statistical analyses, drafting the manuscript. ZFZ: Suggestions for methods and results sections, tables, and figures. .BH: acquisition of data. All authors read and approved the final manuscript.

\section{Funding}

None.

\section{Availability of data and materials}

The datasets used and/or analysed during the current study are available from the corresponding author on reasonable request.

\section{Ethics approval and consent to participate}

The study was approved by the local Ethics Committee (The Ethical Committee of Ningbo N0.7 Hospital). Written Informed consent to participate in the study was obtained from participants.

\section{Consent for publication}

Not applicable.

\section{Competing interests}

The authors declare that they have no competing interests.

\section{Author details}


${ }^{1}$ Department of Anesthesiology, Ningbo NO.7 Hospital, Zhejiang Province, China

${ }^{2}$ Department of Anesthesiology, Zhejiang Provincial People's Hospital (People's Hospital of Hangzhou Medicine College), Zhejiang Province, China

${ }^{3}$ Department of Gynecology, Ningbo NO.7 Hospital, Zhejiang Province, China

${ }^{4}$ Department of Anesthesiology, The Second Affiliated Hospital, Jiaxing University, Zhejiang Province, China

*Corresponding author: Department of Anesthesiology, The Second Affiliated Hospital, Jiaxing University, Zhejiang Province, China

Email囚zqh@jxey.com

\section{References}

1.

Yokoyama K, Suzuki M, Shimada Y, Matsushima T, Bito H, Sakamoto A. Effect of administration of prewarmed intravenous fluids on the frequency of hypothermia following spinal anesthesia for Cesarean delivery. J Clin Anesth. 2009;21:242-8.

2.

Carpenter L, Baysinger CL. Maintaining perioperative normothermia in the patient undergoing cesarean delivery. Obstet Gynecol Surv. 2012;67:436-46.

3.

Petsas A, Vollmer H, Barnes R. Peri-operative warming in Caesarean sections. Anaesthesia. 2009;64:9212.

4.

Butwick AJ, Lipman SS, Carvalho B. Intraoperative forced air-warming during cesarean delivery under spinal anesthesia does not prevent maternal hypothermia. Anesth Analg. 2007;105:1413-9. table of contents.

5 .

Rajagopalan S, Mascha E, Na J, Sessler DI. The effects of mild perioperative hypothermia on blood loss and transfusion requirement. Anesthesiology. 2008;108:71-7.

6.

Melling AC, Ali B, Scott EM, Leaper DJ. Effects of preoperative warming on the incidence of wound infection after clean surgery: a randomised controlled trial. Lancet. 2001;358:876-80.

7.

Kurz A, Sessler DI, Lenhardt R. Perioperative normothermia to reduce the incidence of surgical-wound infection and shorten hospitalization. Study of Wound Infection and Temperature Group. N Engl J Med. 1996;334:1209-15.

8. 
Flores-Maldonado A, Medina-Escobedo CE, Ríos-Rodríguez HM, Fernández-Domínguez R. Mild perioperative hypothermia and the risk of wound infection. Arch Med Res. 2001;32:227-31.

9.

Schmied H, Kurz A, Sessler DI, Kozek S, Reiter A. Mild hypothermia increases blood loss and transfusion requirements during total hip arthroplasty. Lancet. 1996;347:289-92.

10.

Hart SR, Bordes B, Hart J, Corsino D, Harmon D. Unintended Perioperative Hypothermia. Ochsner J. $2011 ; 11: 259-70$.

11.

Frank SM, Fleisher LA, Breslow MJ, Higgins MS, Olson KF, Kelly S, et al. Perioperative maintenance of normothermia reduces the incidence of morbid cardiac events. A randomized clinical trial. JAMA. $1997 ; 277: 1127-34$.

12.

Peng RY, Bongard FS. Hypothermia in trauma patients. J Am Coll Surg. 1999;188:685-96.

13.

Horn E-P, Schroeder F, Gottschalk A, Sessler DI, Hiltmeyer N, Standl T, et al. Active warming during cesarean delivery. Anesth Analg. 2002;94:409-14. table of contents.

14.

Suzuki M, Kinoshita T, Kikutani T, Yokoyama K, Inagi T, Sugimoto K, et al. Determining the plasma concentration of ketamine that enhances epiduralbupivacaine-and-morphine-induced analgesia. Anesth Analg. 2005;101:777-84.

15.

Ozaki M, Kurz A, Sessler DI, Lenhardt R, Schroeder M, Moayeri A, et al. Thermoregulatory thresholds during epidural and spinal anesthesia. Anesthesiology. 1994;81:282-8.

16.

Matsukawa T, Sessler DI, Christensen R, Ozaki M, Schroeder M. Heat flow and distribution during epidural anesthesia. Anesthesiology. 1995;83:961-7.

17.

Hynson JM, Sessler DI. Intraoperative warming therapies: a comparison of three devices. J Clin Anesth. 1992:4:194-9.

18.

Hynson JM, Sessler DI, Moayeri A, McGuire J, Schroeder M. The effects of preinduction warming on temperature and blood pressure during propofol/nitrous oxide anesthesia. Anesthesiology. 1993;79:21928. discussion 21A-22A.

19.

Hui C-K, Huang C-H, Lin C-J, Lau H-P, Chan W-H, Yeh H-M. A randomised double-blind controlled study evaluating the hypothermic effect of 150 microg morphine during spinal anaesthesia for Caesarean section. Anaesthesia. 2006;61:29-31.

20. 
Horn E-P, Bein B, Steinfath M, Ramaker K, Buchloh B, Höcker J. The incidence and prevention of hypothermia in newborn bonding after cesarean delivery: a randomized controlled trial. Anesth Analg. 2014;118:997-1002.

21.

Conforti A, Alviggi C, Mollo A, De Placido G, Magos A. The management of Asherman syndrome: a review of literature. Reprod Biol Endocrinol. 2013;11:118.

22.

Badjatia N, Strongilis E, Gordon E, Prescutti M, Fernandez L, Fernandez A, et al. Metabolic impact of shivering during therapeutic temperature modulation: the Bedside Shivering Assessment Scale. Stroke. 2008;39:3242-7.

23.

Chung SH, Lee B-S, Yang HJ, Kweon KS, Kim H-H, Song J, et al. Effect of preoperative warming during cesarean section under spinal anesthesia. Korean J Anesthesiol. 2012;62:454-60.

24.

Kurz A, Ikeda T, Sessler DI, Larson MD, Bjorksten AR, Dechert M, et al. Meperidine decreases the shivering threshold twice as much as the vasoconstriction threshold. Anesthesiology. 1997;86:1046-54. 25.

Cobb B, Cho Y, Hilton G, Ting V, Carvalho B. Active Warming Utilizing Combined IV Fluid and Forced-Air Warming Decreases Hypothermia and Improves Maternal Comfort During Cesarean Delivery: A Randomized Control Trial. Anesth Analg. 2016;122:1490-7.

26.

de Bernardis RCG, Siaulys MM, Vieira JE, Mathias LAST. Perioperative warming with a thermal gown prevents maternal temperature loss during elective cesarean section. A randomized clinical trial. Braz J Anesthesiol. 2016;66:451-5.

27.

Munday J, Osborne S, Yates P, Sturgess D, Jones L, Gosden E. Preoperative Warming Versus no Preoperative Warming for Maintenance of Normothermia in Women Receiving Intrathecal Morphine for Cesarean Delivery: A Single-Blinded, Randomized Controlled Trial. Anesth Analg. 2018;126:183-9. 28.

Webb PJ, James FM, Wheeler AS. Shivering during epidural analgesia in women in labor. Anesthesiology. $1981 ; 55: 706-7$.

29.

Sultan P, Habib AS, Cho Y, Carvalho B. The Effect of patient warming during Caesarean delivery on maternal and neonatal outcomes: a meta-analysis. Br J Anaesth. 2015;115:500-10. 30 .

Woolnough M, Allam J, Hemingway C, Cox M, Yentis SM. Intra-operative fluid warming in elective caesarean section: a blinded randomised controlled trial. Int J Obstet Anesth. 2009;18:346-51. 31.

Fallis WM, Hamelin K, Symonds J, Wang X. Maternal and newborn outcomes related to maternal warming during cesarean delivery. J Obstet Gynecol Neonatal Nurs. 2006;35:324-31. 


\section{Tables}

Table1.Demographic ,surgical and anesthetic date of the study population.

\begin{tabular}{|c|c|c|}
\hline & Intervention( $\mathrm{n}=68)$ & $\begin{array}{l}\text { Control } \\
(n=64)\end{array}$ \\
\hline Age, $y$ & $28.5 \pm 5.1$ & $27.5 \pm 4.6$ \\
\hline BMI, $\mathrm{kg} / \mathrm{m}^{2}$ & $28.1 \pm 3.2$ & $28.4 \pm 3.4$ \\
\hline Gestation, weeks & $38.6 \pm 1.4$ & $38.7 \pm 1.3$ \\
\hline Gravidity & $2.0[1.0-3.5]$ & $2.0[1.0-3.0]$ \\
\hline Parity & $1.0[0.0-1.0]$ & $1.0[0.0-1.0]$ \\
\hline ASA I/ II & $56(82.4 \%)$ & $52(81.3 \%)$ \\
\hline Estimated blood loss, mL & $272.8 \pm 70.4$ & $267.2 \pm 73.6$ \\
\hline Surgical duration , min & $44.2 \pm 7.5$ & $43.3 \pm 8.3$ \\
\hline Baseline temperature, ${ }^{\circ} \mathrm{C}$ & $36.7 \pm 0.4$ & $36.7 \pm 0.3$ \\
\hline Prespinal temperature, ${ }^{\circ} \mathrm{C}$ & $37.0 \pm 0.3$ & $36.6 \pm 0.3$ \\
\hline Preoperative ambient temperature, ${ }^{\circ} \mathrm{C}$ & $22.6 \pm 0.6$ & $22.9 \pm 0.8$ \\
\hline OR ambient temperature, ${ }^{\circ} \mathrm{C}$ & $23.9 \pm 0.7$ & $24.2 \pm 0.8$ \\
\hline PACU ambient temperature, ${ }^{\circ} \mathrm{C}$ & $23.2 \pm 0.6$ & $22.8 \pm 0.6$ \\
\hline Intraoperative crystalloid ,mL & $1291.2 \pm 246.0$ & $1343.8 \pm 264.2$ \\
\hline
\end{tabular}

Data are mean $\pm \mathrm{SD}$, median [interquartile range], or number $(\%)$.

BMI: body mass index; ASA: American Society of Anesthesiologists; OR: operating room ; PACU: postanesthesia care unit; EBL: estimated blood loss.

Table2.Secondary maternal and neonatal outcomes. 


\begin{tabular}{|c|c|c|c|}
\hline & Intervention $(\mathrm{n}=68)$ & $\begin{array}{l}\text { Control } \\
(n=64)\end{array}$ & $P$ value \\
\hline PACU arrival temperature ${ }^{\circ} \mathrm{C}$ & $36.2 \pm 0.4$ & $35.5 \pm 0.3$ & 0.007 \\
\hline Perioperative shivering & $13(19.1 \%)$ & $36(56.3 \%)$ & $<0.0001$ \\
\hline Shivering assessment score & $0[0-0]$ & $1[0-2]$ & 0.01 \\
\hline Perioperative hyperthermia & $14(20.6 \%)$ & $33(51.6 \%)$ & $<0.0001$ \\
\hline Apgar score & $0[0-0]$ & $1[0-2]$ & 0.01 \\
\hline $1 \mathrm{~min}$ & 9 [9-9] & 9 [9-9] & 0.21 \\
\hline $5 \mathrm{~min}$ & $10[10-10]$ & $10[10-10]$ & 0.43 \\
\hline Neonatal temperature ${ }^{\circ} \mathrm{C}$ & $36.3 \pm 0.3$ & $36.3 \pm 0.4$ & 0.350 \\
\hline
\end{tabular}

Data are mean $\pm \mathrm{SD}$, median [interquartile range], or number (\%).

OR: operating room ; PACU: postanesthesia care unit.

Bedside Shivering Assessment Scale: $0=$ no shivering; $1=$ shivering localized to the core and neck; $2=$ shivering including the upper extremities; $3=$ total body shivering.

\section{Figures}




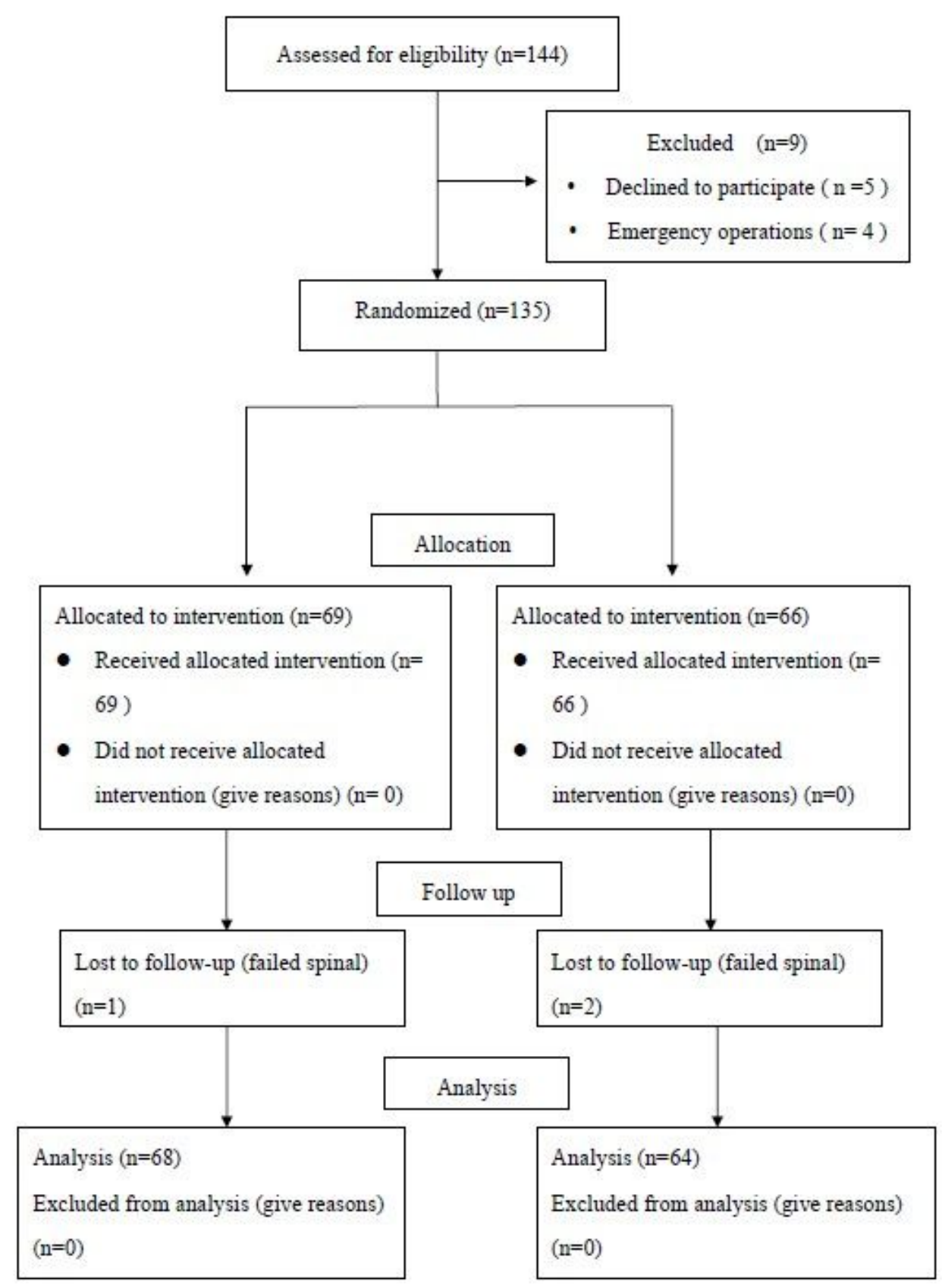

\section{Figure 1}

Flow diagram outlining the enrollment and randomization of the study procedure. 


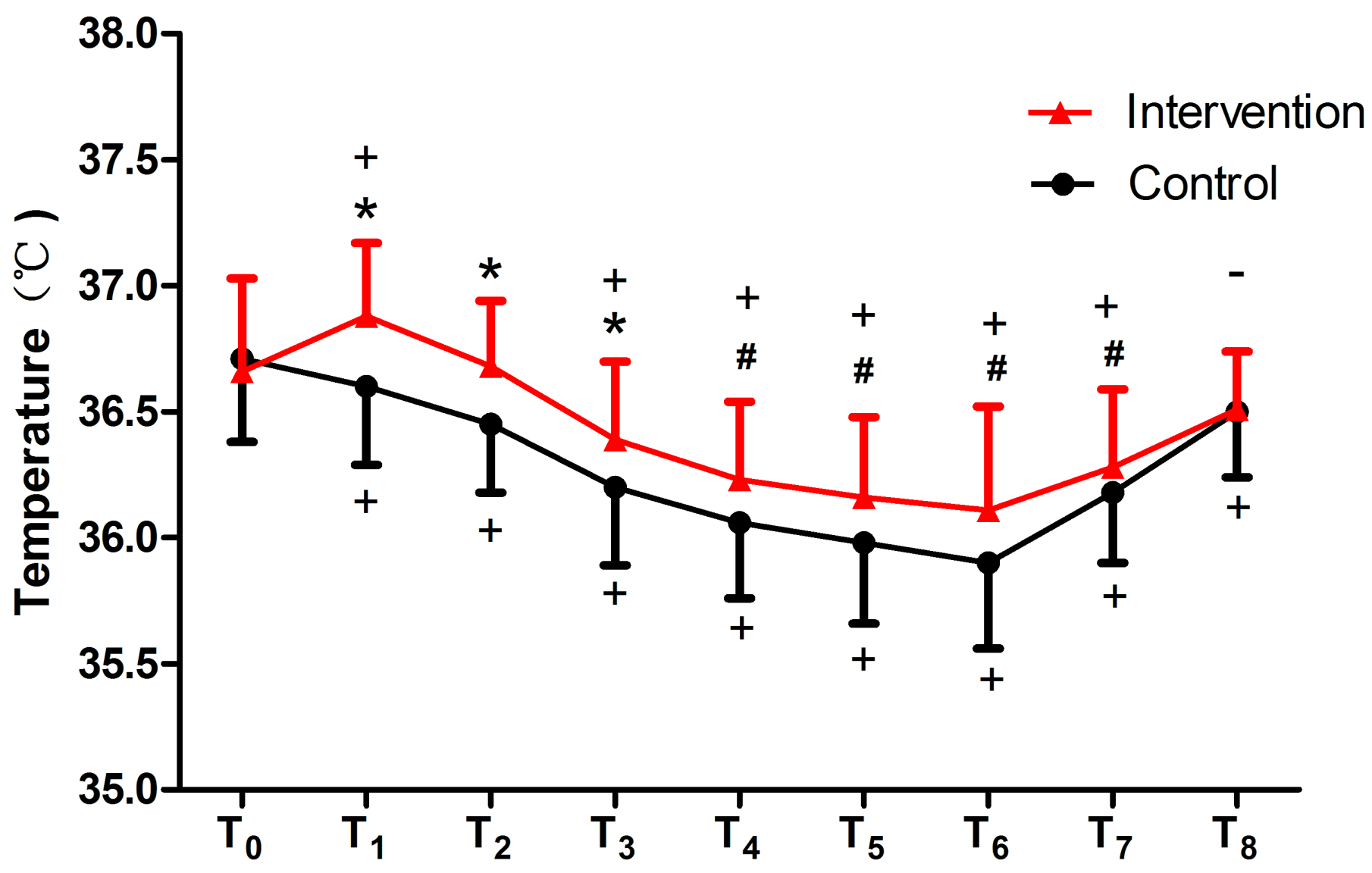

Figure 2

The maternal tympanic temperature in the procedure. $T 0=$ time of baseline, $T 1=$ time of prespinal, $T 2=$ time of postspinal, T3= time of OR 15 minutes,T4= time of OR 30 minutes, T5= time of OR end surgery,T6= time of PACU arrival,T7= time of PACU 15minutes, T8= time of PACU 30minutes. OR: operating room; PACU: postanesthesia care unit. Statistically significant difference between the interventional and control groups, ${ }^{*} P<0.001$. \#P<0.05. Statistically significant difference within groups compared to $\mathrm{T} 0,+\mathrm{P}<0.001,-\mathrm{P}<0.05$. 


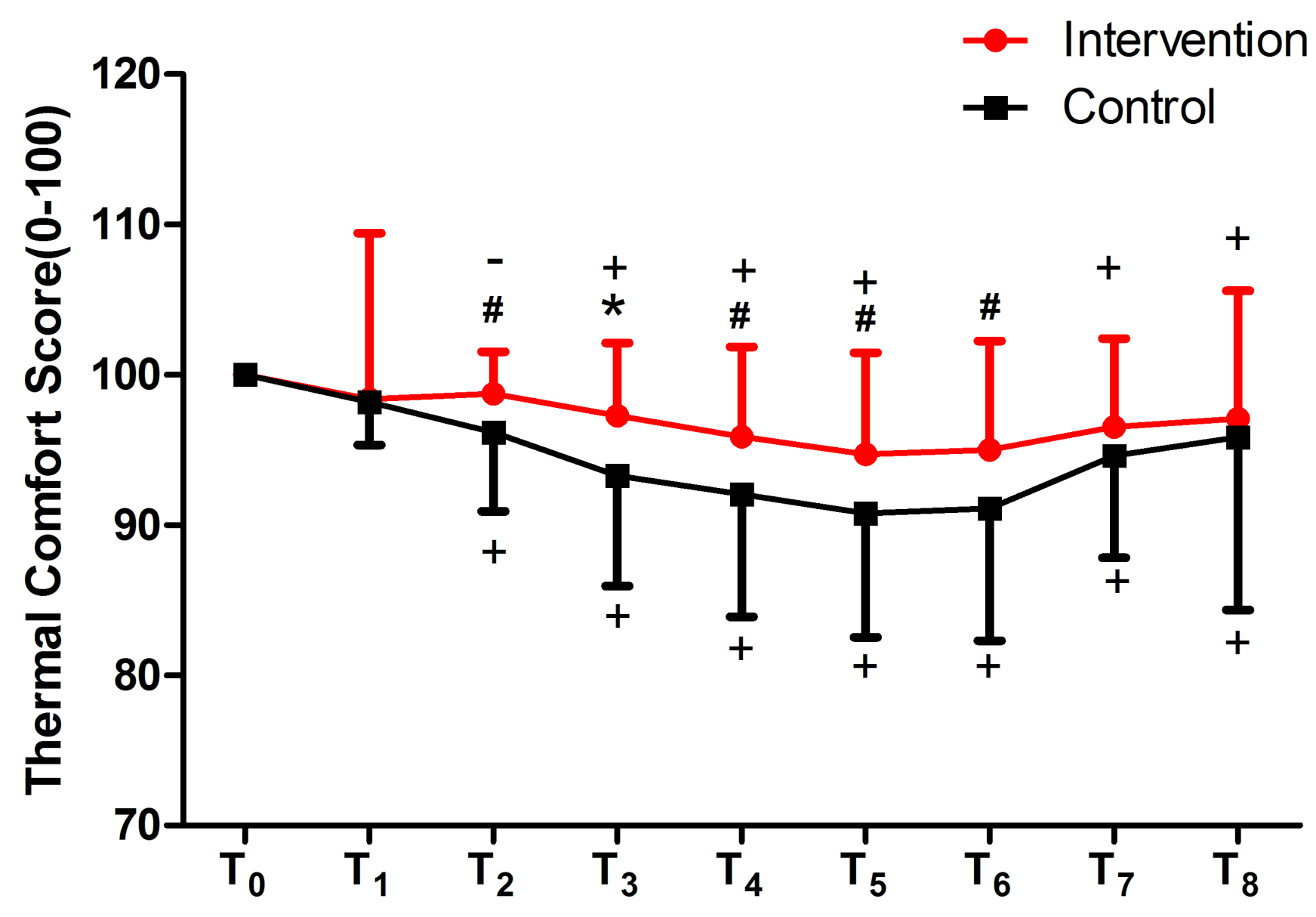

Figure 3

The maternal comfort scores in the procedure. $T 0=$ time of baseline, $\mathrm{T} 1=$ time of prespinal, $\mathrm{T} 2=$ time of postspinal, $T 3=$ time of OR 15 minutes, $T 4=$ time of OR 30 minutes, $T 5=$ time of OR end surgery, $T 6=$ time of PACU arrival,T7= time of PACU 15minutes, T8 = time of PACU 30minutes. Thermal comfort scores was measured using a verbal numerical scale on which 0 was defined as completely unsatisfied with their "thermal comfort", 100 as completely satisfied. Statistically significant difference between the interventional and control groups, ${ }^{\star} P<0.001$. $\# P<0.05$. Statistically significant difference within groups compared to $T 0,+P<0.001,-P<0.05$.

\section{Supplementary Files}

This is a list of supplementary files associated with this preprint. Click to download.

- CONSORTchecklist.doc 